\title{
Unmasking trust issues with field work in a rural community
}

\author{
Marie Josée Ufitamahoro, Isabella M. Venter, William D. Tucker, Carlos Rey-Moreno
}

\begin{abstract}
The principal objective of this paper is to describe the author's fieldwork and research in a remote rural area of South Africa, where a village Telco is deployed to provide VoIP (Voice over Internet Protocol) on a wireless mesh network. The objective of the visit was to evaluate the users social environment and to try to understand trust issues associated with the adoption of the network. Qualitative measures such as contextual inquiry, participant observation, focus group and individual interviews were used during data collection. Focus group discussions were held with community members involved with the planning of ways in which to sustain the network. Involving the community gave them a sense of commitment and ownership of the network. To maintain the network, different solutions were proposed, one of these was a billing system for the use of the network. This will be designed to meet the users needs but should also be transparent so that the community will trust it. A prototype is being developed, with input from the community, using open source software to address the community's requirements. The outcome of the fieldwork initiative was an understanding of the trust issues regarding the usage of the network. This will feed into a framework for the deployment of such services in rural marginalized communities.
\end{abstract}

Keywords: Billing system, Community members, Node stations, Rural communities, Tribal Authority, Trust, Voice over Internet Protocol

\section{Introduction}

It is difficult to imagine life in rural South Africa especially if you are a young female computer scientist from another African country. The Mankosi community is located on the Wild Coast in the Eastern Cape, a province of South Africa. It is a remote rural area where homesteads are far flung and where domestic access to grid electricity or to running water is not provided [1]. The researcher felt that reading literature about this area and about the set-up of the network, it would be possible to understand the rural community, their difficulties and what systems they would require. In real life, which only became apparent once the researcher physically visited the area, it was not at all what she had envisaged. In the city we rely on electricity for all our information communication needs; but this is very difficult in rural communities where only some people (like visitors to the backpackers) have access to electricity, powered by solar panels. The researcher, for example, had to share the energy provided by a 140W solar panel and two 102Ah batteries with four other researchers. It was thus difficult to charge all the required electrical equipment each day. And when it was cloudy or when the sun did not shine, 
all electronic devices had to be unplugged during the day to conserve energy for lights at night. It is thus understandable that community inhabitants would feel that the network will often not be functional and therefore not essential.

The visit to Mankosi was undertaken to experience the physical- and social environment in which a Village Telco network (in a rural setting) operates and to try to understand trust issues associated with the adoption of such a network. Failures - when existing technologies are deployed in rural settings - are abound thus trust in the success of such initiatives is low. Apart from the mobile phones, very few examples exist of the successful deployment of digital technologies. And it is unclear whether these deployments contributed to rural social and economic development [2]. It is important to understand the needs and expectations of the community in terms of information communication technologies for development (ICT4Ds) which can be addressed by these questions: How should the community be included in the design and development of the network for them to take ownership of the network? How should they be incentivized to use the network? Why would such a network be beneficial to the community? What are the major hurdles in sustaining the network?

According to a baseline survey conducted in Mankosi in 2012 [3], community members mostly use mobile phones to call people within the community. For that reason, a solar-powered mesh network was implemented at no cost for the community, and is currently being used by the Tribal Authority in Mankosi. Although the intra-community calls are free, the local Tribal Authority felt that users should be charged a minimal fee, to raise money to help with the maintenance of the network but also to expand the network [3]. The fact that the network is based on open standards should make it easy to expand the network to also provide other services like VoIP breakout and a connection to the Internet.

Although the overall focus of the project is to provide the community with the ability to communicate with each other without making expensive calls, the solar panels that, in the beginning, were intended for powering the telephony system, were found to be used mostly (by the community) for charging cell phones. The solar system was thus expanded to cater for the recharging of phones as well as to provide light emitting diode (LED) lighting for the base stations where the nodes are housed. This service has resulted in lowering the recharging fee currently R5.00 at the local spaza shop - to R3.00 for community members. The revenue generated from charging the phones is currently the principal source of revenue for the network business model [3]. For a better understanding of the current activity on the network and the current use of its services, an ethnography field study was conducted. Through this field study, several trust issues were identified: trust in the use of the generated funds; trust in the Tribal Authority's openness about who may use the network; trust in the ability of people to manage the network and trust in the usability of the network. All of these trust issues affects the usage of the network. 


\section{Methods}

The four main stakeholders of this network project are: the community members, the Tribal Authorities, the network operators and the student researchers. In the field study, several methods of data collection were used: s ethnography, observation and interviews (individual and in focus groups). This provided rich qualitative data.

Initially one main meeting was arranged with the whole Mankosi community, mainly to introduce the aims of the project and to organize individual meetings with smaller focus groups. In small village meetings, the researcher met with the local village dwellers and their respective sub-headman. Currently ten node stations (each with an analogue telephone - also referred to as a mesh potato) are deployed within the twelve villages of the Mankosi community. The researcher participated in two of the 10 scheduled meetings during the time that she was in the field. Many of these meetings were not held or were postponed due to low attendance or due to bad weather conditions - meetings were held outside.

Observation was the preferred technique used to build report with the participants and to provide a platform to crosscheck information and possible differences between what people do and what they say they do. It provided the necessary insight and understanding of how the network services are used within an ICT4D context. To gain new insights or to discover aspects that people may not wish to reveal in focus-group interviews, the researcher visited individual people in the various villages. To facilitate the observation technique, field notes, recordings and pictures were taken to capture what was said and done and to preserve indigenous meanings. A local interpreter was provided since the researcher does not speak the local language (isiXhosa). This compromised some of the interaction with the local users since in the Xhosa culture, women are not supposed to talk first.

Data that was collected, highlighted the following: For the first time all the stakeholders involved with the project could actively debate the usage of the system.

1) The community was ignorant about why the network was being installed and that in fact it was for their use. Most of the community members affirmed that they thought the mesh potatoes of the Village Telco was for Tribal authorities' use only, and that community members could only use it for charging their mobile phones.

2) The community members felt that the mesh potatoes, currently a fixed telephone inside a node-station, would not be very useful, since to make calls, the user would have to go to one of the nodes to call a person without knowing whether the called person would be available. They indicated mobile phones would be preferred, since if the person being called does not pick up, a missed call will notify the person of the call. The community indicated that they now understood the usefulness of the project and would use the mesh potatoes: for emergency calls; to call other villages or to call their tribal authorities to discuss problems regarding the community, or to arrange meetings. 


\section{Future work}

There is a growing demand to understand the needs and expectations of users dwelling in resource constrained areas. To successfully implement a community owned project, particular attention needs to be paid to the maintenance and sustainability of the project. A billing system will generate revenue for the maintenance of the network - and is the method proposed by the Tribal Authority. The major limitation of the field study was the language constraint which might have impacted on the reliability of the data and that some finer nuances of the user experiences were not captured. The methodology used in this work can be used to add value to the deployment of such services in rural or marginalized communities. 


\section{References}

[1] Bidwell, NJ, Lalmas, M, Marsden, G, Dlutu, B, Ntlangano, S, Manjingolo, A, Tucker, WD, ... Klampanos, I (2011). Please call ME.N.U.4EVER: Designing for "Callback” in Rural Africa. IWIPS, 117-137

[2] Kapuire, G. K., Winschiers-Theophilus, H., Chivuno-Kurio, S., Bidwell, N. J., \& Blake, E. (2010). Revolution in ICT, the last hope for African rural communities' technology appropriation.

[3] Rey-Moreno, C, Roro, Z, Tucker, WD, Siya, MJ, Bidwell, NJ, \& Simo-Reigadas, J (2013). Community-based solar power revenue alternative to improve sustainability of rural wireless mesh network. ACM ICTD. 